\title{
O PROGRAMA UNIVERSIDADE PARA TODOS: UM ESTUDO SOBRE A PRODUÇÃO ACADÊMICA - 2007-2019
}

\author{
PROGRAMA UNIVERSIDAD PARA TODOS: UN ESTUDIO SOBRE LA PRODUCCIÓN \\ ACADÉMICA - 2007-2019
}
THE UNIVERSITY FOR ALL PROGRAM: A STUDY ON ACADEMIC PRODUCTION - 2007-2019

\author{
Polyana Raquel PEDROSO ${ }^{1}$ \\ Maria Lourdes GISI ${ }^{2}$
}

RESUMO: A educação superior tem sido objeto de políticas públicas com o intuito de diminuir as desigualdades de acesso a este nível de ensino e uma dessas medidas foi institucionalização do Programa Universidade para Todos - Lei $\mathrm{n}^{0} 11.096 / 2005$. Este programa possibilitou ampliar o acesso, mas ainda sem atender à universalização e sem garantir a permanência daqueles que são beneficiados com bolsas de estudo. Com a oferta já ultrapassando uma década, surgiu o interesse em analisar a produção científica existente no período de 2005-2019, mediante um estudo de revisão narrativa na base de dados da Biblioteca Digital Brasileira de Teses e Dissertações (BDTD). Observou-se que em relação às 94 publicações que compuseram a amostra desse estudo, apenas 31 fazem análise exclusivamente da perspectiva dos estudantes. Também se percebem muitas lacunas na produção do conhecimento sobre, especificamente, as experiências e vivências da inserção e permanência dos estudantes que utilizam bolsas do Prouni.

PALAVRAS-CHAVE: Políticas educacionais. Educação superior. Programa universidade para todos. Prouni.

RESUMEN: La educación superior ha sido objeto de politicas públicas con el fin de reducir las desigualdades en el acceso a este nivel educativo y una de estas medidas fue la institucionalización del Programa Universidad para Todos - Ley 11.096/2005. Este programa permitió ampliar el acceso, pero aún sin atender a la universalización y sin garantizar la permanencia de quienes se benefician de las becas. Con la oferta que ya excedió una década, surgió interés en analizar la producción científica ya existente en el periodo 2007-2019, a través de un estudio de revisión narrativa en la base de datos de la Biblioteca Digital Brasileña de Tesis y Disertaciones (BDTD). Se observó que en relación con las 94 publicaciones que conformaban la muestra de este estudio, solo 31 realizan análisis exclusivamente desde la perspectiva de los estudiantes. También hay muchas lagunas

\footnotetext{
${ }^{1}$ Pontifícia Universidade Católica do Paraná (PUCPR), Curitiba - PR - Brasil. Mestranda no Programa de Pósgraduação em Educação. ORCID: https://orcid.org/0000-0003-1950-3751. $\quad$ E-mail: polyanaraqpedroso@gmail.com

${ }^{2}$ Pontifícia Universidade Católica do Paraná (PUCPR), Curitiba, Curitiba - PR - Brasil. Professora Titular no Programa de Pós-graduação em Educação. Doutorado em Educação (UNESP). ORCID: https://orcid.org/00000002-0474-474X. E-mail: gisi.marialourdes@gmail.com
}

RPGE- Revista on line de Política e Gestão Educacional, Araraquara, v. 25, n. 1, p. 138-148, jan./abr. $2021 . \quad$ e-ISSN:1519-9029 DOI: https://doi.org/10.22633/rpge.v25i1.13988 
en la producción de conocimiento sobre las experiencias especificas de inserción y permanencia de los estudiantes que utilizan las becas Prouni.

PALABRAS CLAVE: Politicas educativas. Educación universitaria. Programa universidad para todos. Prouni.

ABSTRACT: Higher education has been the subject of public policies to reduce inequalities in access to this level of education, one of these measures was the institutionalization of the University for All Program - Law 11.096/2005. This program made it possible to expand access, but still without attending to universalization and without guaranteeing the permanence of those who benefit from scholarships. With the offer already exceeding a decade, interest arose in analyzing the scientific production already existing in the period of 2007-2019, through a narrative review study in the database of the Brazilian Digital Library of Theses and Dissertations (BDTD). It was observed that in relation to the 94 publications that comprised the sample of this study, only 31 make analysis exclusively from the perspective of the students. There are also many gaps in the production of knowledge, specifically, about the experiences of the insertion and permanence of students using Prouni scholarships.

KEYWORDS: Educational policies. Higher education. University for all program. Prouni.

\section{Introdução}

No Brasil, as políticas públicas para a educação superior têm adotado medidas com o intuito de minimizar as desigualdades sociais existentes na realidade brasileira. No entanto, ainda se observa um caráter extremamente desigual, revelando as disparidades de oportunidades de acesso à educação superior dos diferentes grupos sociais, em que nas possibilidades de ingressar em uma universidade espelha-se a condição socioeconômica desses sujeitos (PASTORE; SILVA, 2000).

Historicamente, no Brasil, as universidades têm sido ocupadas pelas elites detentoras de capital econômico, social e cultural, e as classes sociais mais favorecidas têm usufruído dessa instituição para legitimar a posição social que ocupam na estrutura social e ampliar o poder que, em geral, já exercem no conjunto da sociedade (RIBEIRO, 2006; FERNANDES, 2006).

Trevisol e Nierotka (2016, p. 23), afirmam que "as instituições de ensino superior (IES) refletem, como espelhos, as desigualdades e a distribuição desigual do poder na sociedade", pois aos sujeitos com trajetória de vida em classe social menos favorecida e trajetória escolar em instituições públicas, são ofertados os cursos de menor prestígio social nas universidades do país. Ainda, segundo os autores, as ações do governo voltadas ao acesso 
dos grupos minoritários à educação superior somente ganharam espaço nos anos mais recentes, com a criação de várias políticas públicas educacionais, tanto em âmbito privado quanto público.

Nas instituições privadas foi aprovado o Programa Universidade para Todos - Lei $\mathrm{n}^{\circ}$ 11.096/2005, que é uma política de acesso à educação superior, com o objetivo de conceder bolsas integrais (100\%) e parciais $(50 \%)$, em cursos de graduação, em instituições privadas de educação superior a estudantes brasileiros sem diploma de nível superior (BRASIL, 2005).

Os quadros informativos do sistema oficial do Prouni, no período entre o ano de 2005 até o $2^{\circ}$ semestre de 2018 , apresentam relatórios referentes ao número de vagas, número de bolsistas e a caracterização sociodemográfica. Dos 27 documentos oficiais, em forma de relatórios semestrais, constatou-se a oferta de 3.663.704 vagas durante a história do programa, sendo 55,18\% vagas integrais e 44,81\% vagas parciais. Mas há que se registrar que mais de 1 milhão das vagas ofertadas pelo programa não foram preenchidas durante o período investigado (BRASIL, 2019).

Muitos dos estudantes que conseguiram o acesso à educação superior por meio de bolsa do Prouni encontram-se nos cursos de menor procura, pois apenas conseguiram a nota mínima no Exame Nacional do Ensino Médio (ENEM). Conforme Bourdieu e Champagne (1998, p. 224) esses estudantes são os "excluídos do interior", pois quando ingressam na educação superior, correm o risco de não ter condições de permanecer no ambiente universitário, devido as inúmeras dificuldades que enfrentam em relação ao capital econômico, social e cultural (EZCURRA; 2011; PAULA, 2017).

Para Mena (2004), o Prouni é comumente visto como mais uma política pública, voltada para ampliar o acesso, mas destaca o fato de manter um sistema de ensino nos moldes privatizantes traçados durante os anos 1990. Nesse sentido, este programa traz uma noção falsa de democratização, pois legitima a distinção dos estudantes por camada social, de acordo com o acesso aos diferentes tipos de instituições (prioridade para a inserção precária dos pobres no espaço privado), ou seja, contribui para a manutenção da estratificação social existente. Sendo assim, favorece o acesso à educação superior, mas não oferece mais do que "uma ilusão e/ou uma promessa não cumprida", já que as bolsas que oferecem gratuidade nas mensalidades não são suficientes para a manutenção e os cursos escolhidos na maioria das vezes são aqueles cujos diplomas não são valorizados socialmente (CARVALHO, 2006, p. 996).

Considerando a abrangência do programa, com a oferta já ultrapassando uma década, surgiu o interesse em pesquisar a produção científica já existente sobre ele. A questão que 
guiou este estudo foi: Quais são as instituições que mais produzem pesquisas científicas sobre o Prouni? O objetivo desse estudo foi analisar a produção científica sobre o Programa Universidade para Todos.

\section{Método}

Foi realizado um estudo de revisão narrativa, realizando o mapeamento da produção científica de dissertações de mestrado e teses de doutorado na base de dados da Biblioteca Digital Brasileira de Teses e Dissertações (BDTD) (BRASIL, 2014), tendo como abrangência temporal o período de 2005-2019 (em vista de o Prouni ser institucionalizado pela Lei n. 11.096/2005).

Os descritores utilizados na busca foram "Programa Universidade para Todos" e "Prouni" e, para ambos, foi aplicada a constatação da palavra no título da publicação. Os critérios de seleção utilizados foram: ter a palavra "Prouni" no título da publicação; o assunto da publicação deveria ser o Prouni; seu resumo e o arquivo na íntegra deveriam estar disponíveis. Os critérios de exclusão foram: publicações indisponíveis, duplicações; idiomas diferentes do português.

Figura 1 - Fluxograma da revisão narrativa

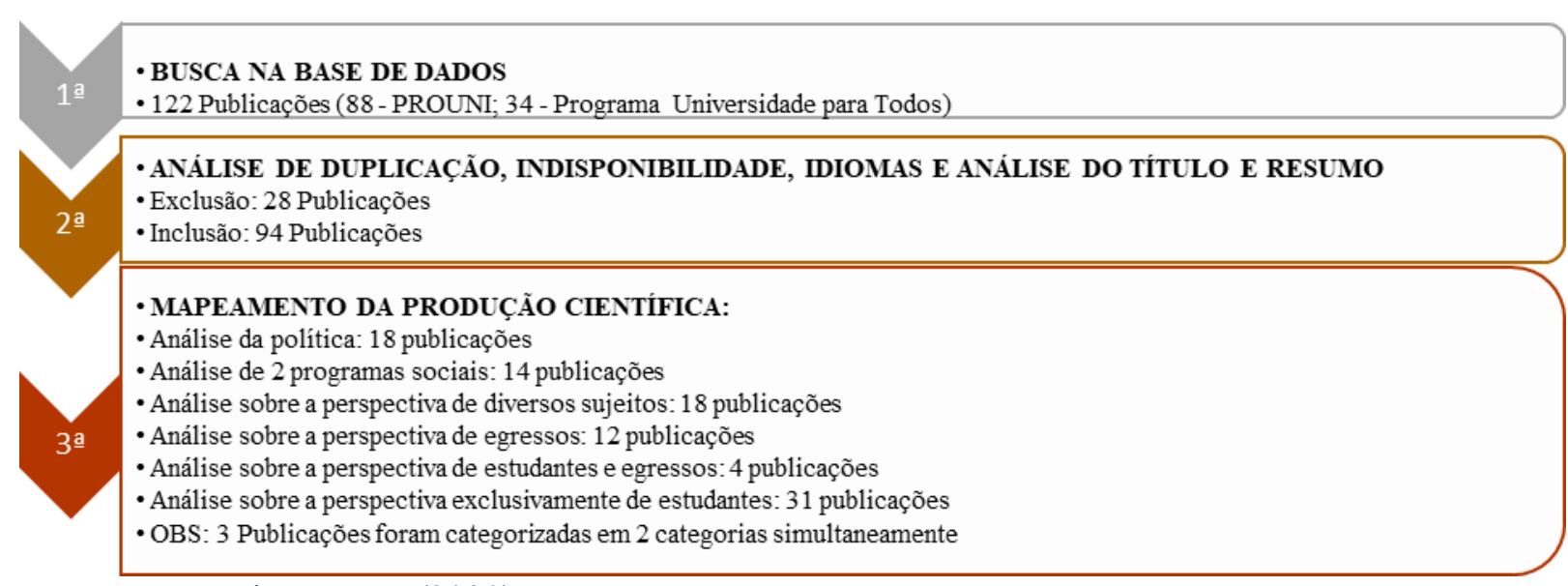

Fonte: Acervo das autoras (2020)

Os procedimentos foram realizados pelas seguintes etapas: 1- exportação da base de dados; 2- criação de planilhas para cada descritor; 3- junção dos descritores; 4- exclusão de duplicações; 5- exclusão de indisponíveis; 6- exclusão de outros idiomas; 7- análise de títulos; 8- análise de resumos; 9- construção da lista das publicações inclusas e exclusas da revisão; 10- coleta de dados nas publicações inclusas (resumo, introdução, encaminhamento 
metodológico); 11- construção de planilhas para análise dos dados coletados (objetivo; aporte teórico; metodologia; abordagem; tipo de pesquisa; técnicas; ferramentas; procedimentos; participantes; amostra; instituições); 12- elaboração de quadros com os dados da pesquisa; 13 construção de categorias a partir dos objetos de estudo das pesquisas documentais (A- análise da política - Prouni; B- análise de dois programas sociais); e partir dos participantes das pesquisas empíricas (C- análise sobre a perspectiva de diversos sujeitos do ambiente universitário - gestores, coordenadores, estudantes, egressos, pais dos estudantes -; D- análise sobre a perspectiva somente de egressos; E- análise sobre a perspectiva de estudantes regularmente matriculados com egressos; F- análise sobre a perspectiva somente de estudantes regularmente matriculados).

\section{Resultados e discussão}

Após aplicados os critérios de inclusão e de exclusão, foram selecionadas 94 publicações e, destas, 71 eram dissertações de mestrado, correspondente a 76\%, e 23 teses de doutorado (24\%). As publicações encontradas datavam do ano de 2007-2019. Demonstrou-se que a temática se mostra um campo de grande interesse de investigação após dois anos de sua institucionalização, sendo que o ano com maior índice de publicações foi o de 2009, conforme indicado na Figura 2.

Figura 2 - Gráfico: Ano das publicações

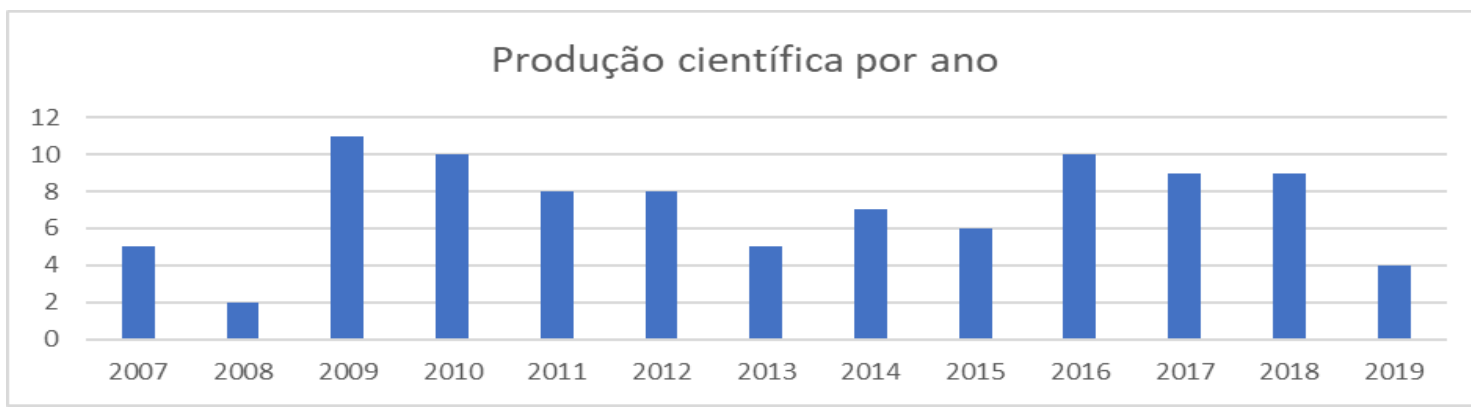

Fonte: Fonte: Acervo das autoras (2020)

Foram encontradas 15 áreas do conhecimento com produção sobre a temática e a que se destacou com maior quantidade de publicações durante o período investigado foi a Educação, seguida das Ciências Sociais, conforme indicado na Figura 3 a seguir. 
Figura 3 - Gráfico: Produção por área do conhecimento

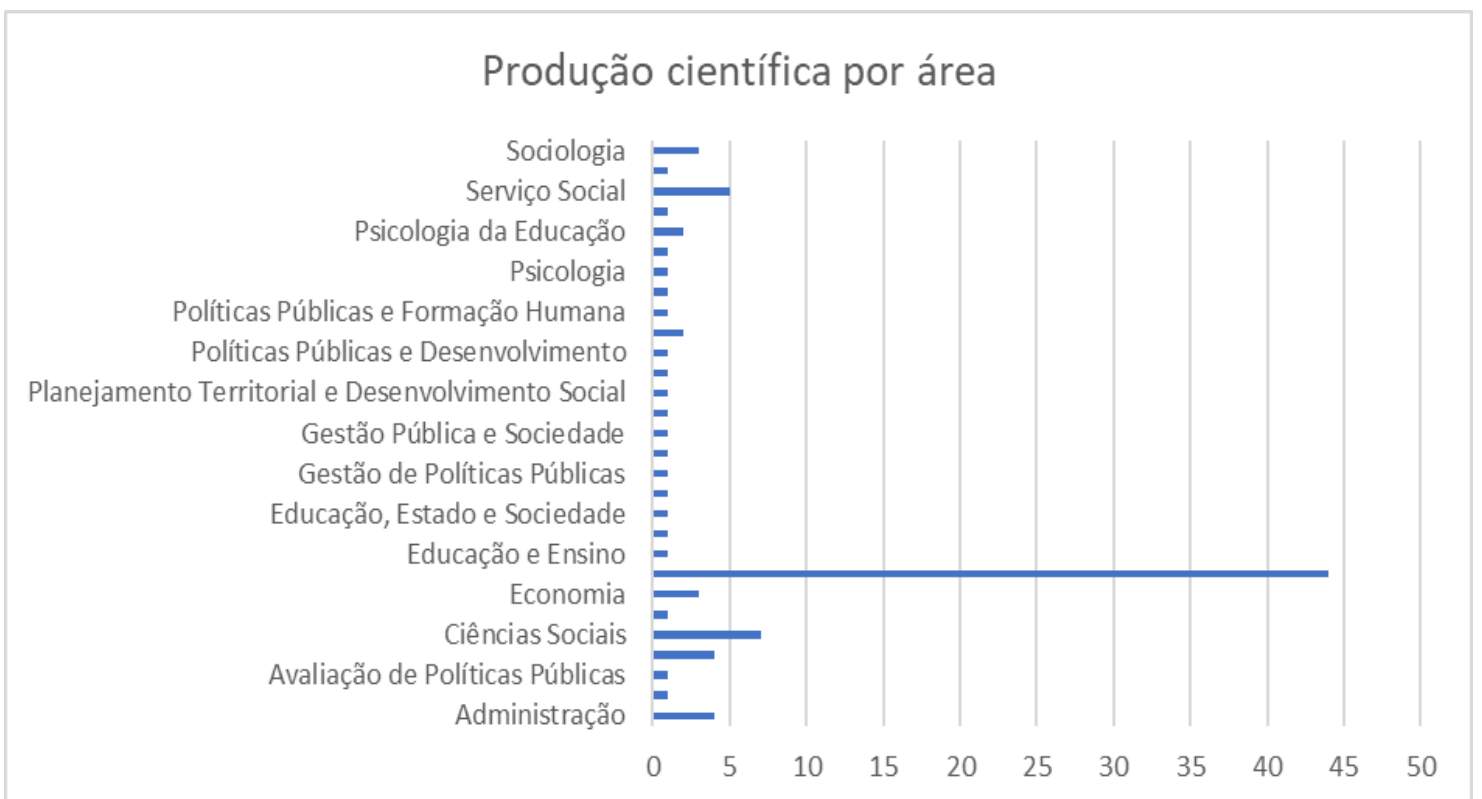

Fonte: Fonte: Acervo das autoras (2020)

A Figura 4 demonstra que esse estudo encontrou 39 instituições universitárias que produziram publicações sobre a temática. A Pontifícia Universidade Católica de São Paulo (PUCSP) foi a instituição com maior produção durante o período investigado, seguida da Universidade Federal do Ceará (UFCE), a segunda instituição com maior publicação, sendo a Universidade do Vale do Rio dos Sinos (UNISINOS) a terceira instituição e a Universidade de São Paulo (USP) a quarta instituição com maior produção científica relacionada a essa temática.

Figura 4 - Gráfico: Instituições com publicações relacionadas à temática

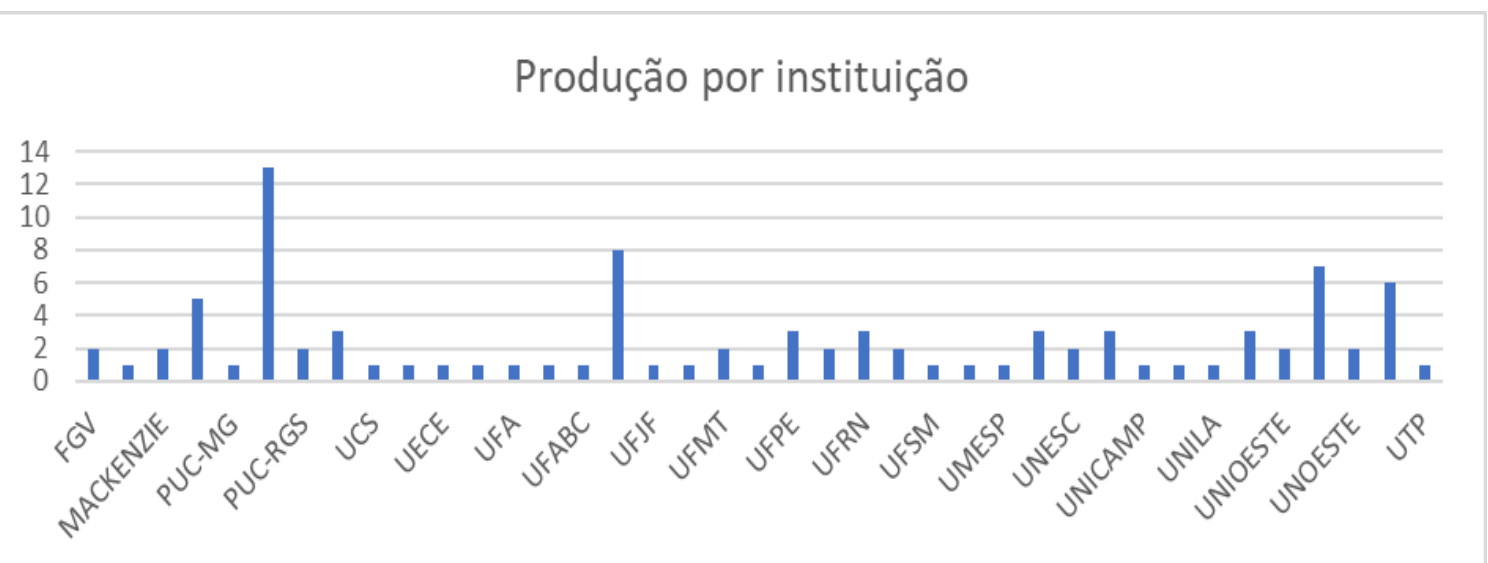

Fonte Fonte: Acervo das autoras (2020) 
Verificou-se a presença de 14 estados brasileiros, sendo que o estado com maior produção de publicações foi São Paulo, seguido do estado do Rio Grande do Sul e do Ceará.

Figura 5 - Gráfico: Publicações por Estado da Federação

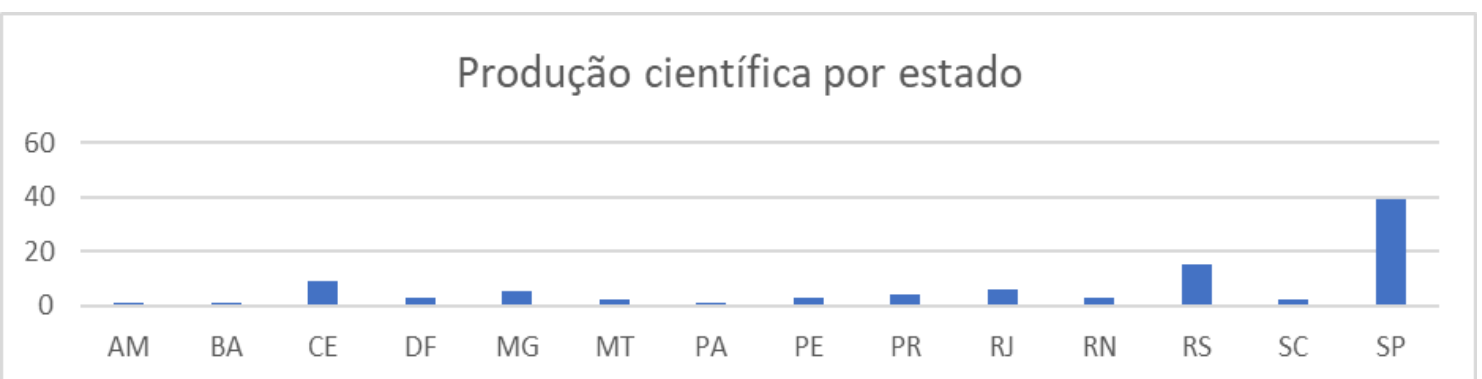

Fonte: Acervo das autoras (2020)

O estado de São Paulo, durante toda a história do Prouni, foi o que mais ofertou bolsas e que teve o maior número de bolsistas, fatos esses que devem se correlacionar com a descoberta desse estudo, pois o estado de São Paulo é o que mais produziu pesquisas sobre o Prouni.

\section{A. Análise da política do Prouni (gestão e avaliação)}

Nessa categoria, foram encontradas 18 publicações e, destas, três são teses de doutorado e 15 dissertações de mestrado. Foram encontradas 13 áreas temáticas entre as teses e dissertações, mas houve predominância em estudos da área da Educação. Verificou-se que esse fenômeno começa a ser estudado a partir do ano 2007 e somente nos anos de 2008, 2010, 2011, 2014, 2015 não houve publicações sobre essa temática. O maior número de publicações foi encontrado no ano de 2009. Das instituições de pesquisa, as que mais publicaram esses estudos foram a Universidade do Vale do Rio dos Sinos (UNISINOS), a Universidade de São Paulo (USP) e a Universidade Federal de Pernambuco (UFPE), com duas publicações cada uma delas. Entre os estados, encontraram-se 10 estados com produção na temática, entretanto, verificou-se que foi o estado de São Paulo que apresentou o maior índice de publicações.

\section{B. Análise comparativa entre dois programas sociais, sendo um deles o Prouni}

Nessa categoria, foram encontradas 14 publicações, sendo que todas eram dissertações de mestrado. Das áreas temáticas dessas publicações, foram encontradas oito áreas, mas a de maior predominância foi a da Educação. Verificou-se que esse fenômeno começa a ser estudado a partir do ano 2007. Nos anos de 2008, 2011, 2012, 2013, 2014 não houve publicações sobre essa temática. O maior número de publicações foi encontrado no ano de 
2016 e de 2018. Foram encontradas 10 instituições universitárias produzindo sobre essa temática, sendo que a que mais publicou foi a Pontifícia Universidade Católica de São Paulo (PUCSP). Dos cinco estados pesquisados, o de maior índice de publicações foi o de São Paulo, com seis publicações.

\section{Análise da perspectiva de diversos sujeitos do ambiente universitário}

Nessa categoria, foram encontradas 18 publicações e, destas, sete eram teses de doutorado e 11 dissertações de mestrado. Das áreas temáticas das teses, a mais encontrada foi da Educação. Verificou-se que esse fenômeno começa a ser estudado a partir do ano de 2007. Nos anos de 2012 e 2018 não houve publicações sobre essa temática. O maior número de publicações foi encontrado nos anos de 2010, 2014 e 2015. Das instituições de pesquisa, a que mais publicou sobre esses estudos foi a Universidade Federal do Rio Grande do Norte (UFRN), com três estudos. Do número de publicações por Estado, São Paulo foi o que apresentou maior índice, com seis publicações.

\section{Análise da perspectiva de egressos do Prouni}

Nessa categoria, foram encontradas 12 publicações e, destas, três são teses de doutorado e nove dissertações de mestrado. Das áreas temáticas, a mais citada foi a Educação. Verificou-se que esse fenômeno começa a ser estudado a partir do ano 2012. Desde o período que começaram essas produções, somente no ano de 2014 não houve publicações sobre essa temática. O maior número de publicações foi encontrado nos anos de 2016 e de 2018. Das instituições de pesquisa, a que mais publicou esses estudos foi a Pontifícia Universidade Católica de São Paulo (PUCSP). Do número de publicações por Estado, São Paulo foi o que apresentou maior índice, com seis publicações.

\section{E. Análise da perspectiva de egressos com estudantes regularmente matriculados}

Nessa categoria, foram encontradas quatro publicações e, destas, duas são teses de doutorado e duas dissertações de mestrado. Desde o período que começaram essas produções, nos anos de 2011, 2012, 2013, 2015, 2016, 2017 e 2019 não houve publicações sobre essa temática. O maior número de publicações foi encontrado no ano de 2018. Encontraram-se estudos em quatro instituições diversas. Do número de publicações por Estado, São Paulo foi o que apresentou maior índice, com três publicações.

\section{F. Análise da perspectiva exclusivamente de estudantes regularmente matriculados}


Nessa categoria, foram encontradas 31 publicações e, destas, nove eram teses de doutorado e 22 dissertações de mestrado. Das áreas temáticas das teses e dissertações, grande parte é da Educação. Verificou-se que esse fenômeno começa a ser estudado a partir do ano 2007. Somente nos anos de 2018 e de 2019 não houve publicações sobre essa temática. O maior número de publicações foi encontrado no ano de 2011. Das instituições universitárias, a que mais publicou esses estudos foi a Pontifícia Universidade Católica de São Paulo (PUCSP), com sete estudos.

\section{Estudos classificados em duas categorias simultaneamente}

Das publicações analisadas nesse estudo, apenas três publicações foram categorizadas em duas categorias simultaneamente, sendo uma publicação classificada na categoria de análise comparativa de dois programas sociais e também na categoria de análise sobre a perspectiva de egressos do Prouni; outra publicação foi classificada na categoria de análise comparativa de dois programas sociais e na categoria de análise sobre a perspectiva egressos e de estudantes regularmente matriculados; e outra publicação foi classificada na categoria de análise da perspectiva de diversos sujeitos do ambiente universitário e na categoria de análise da política.

\section{Considerações finais}

Considerando o estudo realizado, observou-se que em relação às 94 publicações que compuseram esta amostra, apenas 31 fizeram análise exclusivamente da perspectiva dos estudantes regularmente matriculados que utilizam o programa. Ainda há muitas lacunas na produção do conhecimento específico sobre as experiências e as vivências da inserção e da permanência dos estudantes que utilizam bolsas do Prouni.

Acredita-se que a análise de políticas de acesso e permanência da educação superior vem se apresentando como importante temática de pesquisa, uma vez que o estabelecimento de um campo de discussão sólido poderá contribuir para melhor compreensão do processo, tornando-se fator imprescindível para a redução índices de evasão, o que, em última instância, coopera para a ampliação do acesso à educação superior no país.

Os estudos relacionados às políticas para a educação superior vêm sendo alvo de um número cada vez mais elevado de produções acadêmico-científicas, visto que as duas últimas décadas se configuraram como um período fértil para a consolidação de tais estudos, já que 
novas possiblidades de pesquisa foram vislumbradas a partir de incrementos relevantes na formulação e na implementação de políticas para acesso à educação superior.

Assim, a discussão mencionada no presente estudo assume relevância no atual contexto, considerando que a ampliação das políticas de expansão do acesso e da permanência na educação superior pressupõe o acompanhamento sistemático dos sujeitos que ingressam no sistema e, também, de avaliações dessas políticas com o intuito de otimizar a implementação efetiva de tais políticas no país.

Faz-se necessário, então, novas pesquisas para analisar os resultados dessas publicações, a fim de compreender as peculiaridades de cada região do país, de cada Estado, de cada município, de cada instituição de educação superior, de cada área de conhecimento, de cada curso e, por fim, de cada estudante, com vistas a ampliar o olhar sobre os processos de acesso à permanência na educação superior.

\section{REFERÊNCIAS}

BOURDIEU, P.; CHAMPAGNE, P. Os excluídos do interior. In: NOGUEIRA, M. A.; CATANI, A. (Org.). Escritos de educação. Petrópolis: Vozes, 1998.

BRASIL. BDTD. Biblioteca Digital Brasileira de Teses e Dissertações. 2014. Disponível em: http://bdtd.ibict.br/vufind/. Acesso em: 2 maio 2020.

BRASIL. Lei n. 11.096, de 13 de janeiro de 2005. Institui o Programa Universidade para Todos - PROUNI, regula a atuação de entidades beneficentes de assistência social no ensino superior; altera a Lei $\mathrm{n}^{\mathrm{o}} 10.891$, de 9 de julho de 2004, e dá outras providências. Brasília, DF, 14 jan. 2005. Disponível em: http://www.planalto.gov.br/ccivil_03/_Ato20042006/2005/Lei/L11096.htm. Acesso em: 7 maio 2020.

BRASIL. Ministério da Educação. SIS/PROUNI: dados e estatísticas. 2019. Disponível em: http://prouni.mec.gov.br/prouni2006/login/. Acesso em: 21 dez. 2019.

CARVALHO, Cristina Helena Almeida. O PROUNI no governo Lula e o jogo político em torno do acesso ao ensino superior. Educação \& Sociedade, Campinas, v. 27, n. 96, p. 9691000, out. 2006. Disponível em: https://www.scielo.br/pdf/es/v27n96/a16v2796.pdf. Acesso em: 29 set. 2020.

EZCURRA, Ana Maria. Masificación y enseñanza superior: una inclusión excluyente. Algunas hipótesis y conceptos clave. In: FERNÁNDEZ LAMARRA, N. F.; PAULA, M. F. C. (Org.). La democratización de la educación superior en América Latina. Límites y posibilidades. Saenz Peña: EDUNTREF, 2011.

FERNANDES, F. A revolução burguesa no Brasil: ensaio de interpretação sociológica. São Paulo: Globo, 2006. 
MENA, F. Pareceres da FGV e de consultoria divergem sobre número de vagas. Folha de S. Paulo, 17 dez. 2004, Cotidiano. Disponível em:

https://www1.folha.uol.com.br/folha/educacao/ult305u16741.shtml. Acesso em: 19 jul. 2020.

PASTORE, J.; SILVA, N. V. Mobilidade social no Brasil. São Paulo: Makron Books, 2000.

PAULA, M. F. C. Políticas de democratização da educação superior brasileira: limites e desafios para a próxima década. Avaliação Campinas, Sorocaba, v. 22, n. 2, p. 301-315, mai./ago. 2017. Disponível em: https://www.scielo.br/pdf/aval/v22n2/1982-5765-aval-22-0200301.pdf. Acesso em: 19 jul. 2020.

RIBEIRO, D. O povo brasileiro: a formação e o sentido do Brasil. São Paulo: Companhia das Letras, 2006.

TREVISOL, J. V.; NIEROTKA, R. L. Os jovens das camadas populares na universidade pública: acesso e permanência. Rev. Katálysis, Florianópolis, v. 19, n. 1, p. 22-32, jan./jun. 2016. Disponível em: https://www.scielo.br/pdf/rk/v19n1/1414-4980-rk-19-01-00022.pdf. Acesso em: 19 jul. 2020.

\section{Como referenciar este artigo}

PEDROSO, P. R.; GISI, M. L. O Programa Universidade para Todos: um estudo sobre a produção acadêmica - 2007-2019. Revista on line de Política e Gestão Educacional, Araraquara, v. 25, n. 1, p. 138-148, jan./abr. 2021. e-ISSN:1519-9029. DOI: https://doi.org/10.22633/rpge.v25i1.13988

Submetido em: 13/05/2020

Revisões requeridas em: 25/07/2020

Aceito em: 09/11/2020

Publicado em: 02/01/2021 